\title{
Addendum: Mechanical regulation of cell function with geometrically modulated elastomeric substrates
}

\author{
Jianping Fu, Yang-Kao Wang, Michael T Yang, Ravi A Desai, Xiang Yu, Zhijun Liu \& Christopher S Chen \\ Nat. Methods 7, 733-736 (2010); published online 1 August 2010; addendum published after print 28 January 2011.
}

In the version of this article initially published, the implication that it was the first work to decouple substrate rigidity from surface properties was incorrect, as we and others had previously reported the approach. Additional reference to previous work on micropost arrays also should have been included ${ }^{1}$. Our fabrication process, in which micropost arrays are doubly replica molded from microfabricated silicon masters, scales up production of these substrates and allows replication and distribution of disposable molds to potential users.

1. Saez, A., Buguin, A., Silberzan, P. \& Ladoux, B. Biophys. J. 89, L52-L54 (2005).

\section{Corrigendum: Two-photon calcium imaging from head-fixed Drosophila during optomotor walking behavior}

Johannes D Seelig, M Eugenia Chiappe, Gus K Lott, Anirban Dutta, Jason E Osborne, Michael B Reiser \& Vivek Jayaraman Nat. Methods 7, 535-540 (2010); published online 6 June 2010; corrected after print 10 January 2011.

In the version of this article initially published, the units for angular position (degrees) in Figure 3a,b are incorrect. The correct unit should be $\mathrm{mm}$. The error has been corrected in the HTML and PDF versions of the article.

\section{Erratum: Salience}

\section{Bang Wong}

Nat. Methods 7, 773 (2010); published online 29 September 2010; corrected after print 15 December 2010.

In the version of this article initially published, a portion of Figure 1 was missing. The error has been corrected in the HTML and PDF versions of the article. 